\title{
O médico, o seu doente e... Balint
}

Inês Maio*

\section{RESUMO}

Introdução: A relação médico-doente mantém-se objecto de permanente análise, dada a sua complexidade e a sua capital importância no sucesso terapêutico. $O$ relato deste caso exemplifica uma relação médico-doente em que as prioridades do médico e do doente são opostas, e a forma como isso interfere no sucesso da relação terapêutica. Com o relato deste caso, pretende-se ilustrar um exemplo da diversidade das histórias em Medicina Geral e Familiar, especialidade caracterizada pela permanente e complexa interacção de raciocínios médicos e emoções.

Descrição do Caso: Utente do sexo masculino, 28 anos de idade, natural de Cabo Verde, que aos 22 anos de idade tem internamento prolongado, com diagnóstico principal de pancreatite aguda necrosada de origem alcoólica. Teve diagnóstico posterior de Diabetes secundária e iniciou insulinoterapia; que abandonou. Retoma as consultas com o seu médico de família em 2008, e refere ter feito «medicamento da terra». Face à avaliação analítica, que mostrou hiperglicemia e $\mathrm{HbA}_{1 C} 16,5 \%$, foi feita uma abordagem no sentido da reintrodução da insulinoterapia, que este recusou determinantemente. Segundo o doente, há 4 anos foi-lhe dito que sem insulinoterapia não sobreviveria muito mais tempo, e como desde essa altura ele está «vivo e sem problemas», não vê necessidade em retomar. Não tendo sido conseguida adesão às propostas terapêuticas e face à gravidade do quadro clínico, foi proposto ao doente que iniciasse seguimento em instituição para diabéticos, pelo que foi referenciado à Associação Protectora dos Diabéticos de Portugal.

Discussão: Este caso gerou um sentimento de frustração por não se ter conseguido alterar o comportamento do doente, que conduziria a consequências devastadoras, à luz da medicina actual. Numa reflexão baseada no ciclo de mudança, procede-se a uma análise sobre a forma como a Entrevista Motivacional poderia ter determinado um resultado diferente. É descrita a experiência da partilha deste caso numa sessão do grupo Balint, que foi fundamental para ultrapassar a sensação de frustração gerada e também pelas propostas que foram surgindo ao longo da discussão.

É unânime que o MF cuida de indivíduos no contexto das suas famílias, comunidades e culturas, respeitando sempre a autonomia dos seus doentes. Mas que fazer quando a sua autonomia os coloca em risco de vida?

Palavras-chave: Relação Médico-Doente; Balint; Função Apostólica; Ciclo de Mudança; Entrevista Motivacional; Diabetes.

\section{INTRODUÇÃO}

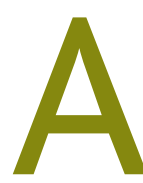

relação médico-doente mantém-se objecto de permanente análise, dada a sua complexidade e a capital importância no sucesso terapêutico. $O$ relato deste caso pretende descrever uma situação de conflito entre o princípio da beneficência dos médicos e a auto-determinação dos doentes. O desejo do médico foi encontrar uma atitude equilibrada que respeitasse o doente e os seus valores conseguindo o melhor plano terapêutico, o que não foi conseguido numa primeira abordagem, pelo que foi necessário gerir um sentimento de frustração gerado pela sensação de dever não cumprido. É descrita a expe-

*Médica Interna de Medicina Geral e Familiar

Centro de Saúde da Amora riência da partilha de um caso numa sessão do grupo Balint, em que se trabalha no sentido da melhoria da relação terapêutica médico-doente, através da discussão entre todos os presentes, que lançam novas visões sobre o problema, atribuindo-lhe outras significações, recontextualizando-o e criando alternativas para a sua solução. ${ }^{1}$ Com o relato deste caso, pretende-se ilustrar um exemplo da riqueza da relação médico-doente e da diversidade das histórias em Medicina Geral e Familiar, especialidade caracterizada pela permanente e complexa interacção de raciocínios médicos e emoções. ${ }^{2}$

\section{DESCRIÇÃO DO CASO}

A., utente do sexo masculino, 28 anos de idade, raça negra, natural de Cabo Verde, pintor da construção civil, 
com história de internamento, aos 22 anos, em Unidade de Urgência Médica de Hospital de São José, durante 28 dias (em Setembro de 2002), com diagnósticos de:

- Pancreatite aguda alcoólica necrosada (com 4 critérios de Ranson e 5 critérios de Glasgow às 48 horas);

- Insuficiência renal aguda com necessidade de hemodiálise em internamento;

- Pneumonia nosocomial a Staphylococcusaureusmeticilino-resistente;

- Ventilação mecânica durante 11 dias;

- Hipertensão arterial de etiologia a esclarecer.

Foi posteriormente transferido para o Serviço da Gastrenterologia do Hospital Garcia de Orta, onde permaneceu durante 7 dias, tendo sido referenciado para consulta externa desta especialidade.

\section{Primeira Consulta com o Médico de Família}

(3 de Dezembro de 2002)

O utente recorreu à consulta do seu Médico de Família (MF), pela primeira vez a 03/12/2002, uns dias antes da primeira consulta de Gastrenterologia, por queixas de lesões vesiculares ao nível da face, e para entregar a nota de alta do internamento. Apresentava lesões compatíveis com acne e da restante observação salienta-se tensão arterial de 140/90 mmHg.

Foi feito o ensino de medidas gerais para tratamento do acne e prescrita medicação tópica. Fez-se o reforço da importância da abstinência alcoólica. Solicitou-se o registo da tensão arterial em ambulatório e pediu-se ao doente que trouxesse informação clínica da consulta externa.

\section{Entre 2002 e 2008}

Alguns dias depois, a companheira de A. veio informar o Médico de Família que A. tinha diagnóstico de Diabetes secundária e que tinha iniciado insulinoterapia. Desde Dezembro de 2002 até Fevereiro de 2008, a única informação que o Médico de Família teve foi através da companheira de A.. Segundo ela, A. teria abandonado a consulta de Gastrenterologia e a insulinoterapia ao fim de 2 anos e recusava quaisquer consultas médicas. Os contactos com esta família nuclear, em Fase III de Duvall, ao longo destes anos foram sobretudo consultas de saúde infantil às duas filhas do casal (nascidas em 1999 e 2001).

\section{Consulta no Serviço de Atendimento Permanente (17 de Fevereiro de 2008)}

Em 17 de Fevereiro do 2008, A. recorre à consulta do Serviço de Atendimento Permanente por queda com traumatismo torácico com queixas de toracalgia, onde lhe é prescrito anti-inflamatório não esteróide, requisita-se radiografia de tórax (sem relatório) e recomenda-se consulta com o médico de família. De salientar que a médica que efectuou a consulta no SAP conhecia os antecedentes do doente, pelo que reforçou a importância de mostrar o exame ao seu MF, de forma a se restabelecer o contacto com este doente.

\section{Segunda Consulta com o Médico de Família}

(18 de Fevereiro de 2008)

No dia seguinte (18/02/2008), A. recorreu ao seu MF para mostrar o resultado do exame radiológico. Quando questionado acerca da Diabetes, refere ter sido seguido em consulta externa de Diabetes e ter efectuado insulinoterapia, que abandonou ao fim de 2 anos, tendo iniciado «medicamento da terra» (aparente derivado de uma raíz africana). Não tem efectuado qualquer vigilância clínica e recusa de forma determinada retomar insulinoterapia.

Do exame objectivo, salienta-se tensão arterial 140/90 mmHg, e a radiografia não apresentava sinais de fractura.

Foi aconselhado o calor húmido e repouso, bem como a manutenção do AINE prescrito anteriormente. Fez-se o reforço da importância da adesão às recomendações de vigilância e terapêuticas e foi requisitado controlo analítico.

\section{Terceira Consulta com o Médico de Família}

(25 de Fevereiro de 2008)

No dia 25/02/2008, A. recorreu à consulta, que foi efectuada pela médica interna do seu MF. De referir que foi proposto ao utente que a consulta fosse videogravada e se obteve o consentimento escrito.

Os motivos da consulta foram a persistência das queixas atribuíveis ao traumatismo da grelha costal e a apresentação dos resultados analíticos. Quando questionado sobre os hábitos alcoólicos, A. refere manter abstinência total desde o internamento. Mantém recusa determinada de retomar insulinoterapia. Como justificação refere efeitos adversos gastrointestinais (nomeadamen- 
te, náuseas), sensação de cansaço fácil e fraqueza.

Do exame objectivo, salienta-se observação torácica e auscultação cardio-pulmonar sem alterações, com valor tensional de 140/90 mmHg. Dos resultados analíticos, destaca-se glicemia em jejum de $353 \mathrm{mg} / \mathrm{dl}$ e Hemoglobina glicosilada de 16,5\%, com função hepática e renal sem alterações.

Perante tais resultados, é feita uma abordagem no sentido de tentar compreender os motivos da recusa da insulinoterapia. São também descritas as várias complicações da sua doença. Perante isto, A. responde: «nunca senti nada disso!». A. mantém-se firme na sua posição alegando que não quer «medicamentos químicos», que lhe terão dito (um «especialista do corpo inteiro») que «a insulina faz bem a umas coisas e faz mal a outras».

Perante a perplexidade da médica e o aparente alheamento do doente, faz-se a educação sobre as principais complicações da diabetes, usando a lembrança das sessões de hemodiálise em internamento. A. refere, numa posição indiferente, quase deitado na cadeira e de braços cruzados, que na consulta da Diabetes lhe disseram que interromper insulinoterapia levaria à sua morte em menos de 2 anos. Ele exclama que está vivo e que se sente bem já há 4 anos. Diz ter feito «tratamento da terra, de África» e que, com ele, conseguiu o controlo dos valores de glicemia.

Quando confrontado com a aparente ineficácia do «medicamento da terra», A. refere que está sem o medicamento há algum tempo e aguarda que este chegue de África. Acredita inclusive, que o «medicamento da terra» tem o poder de restabelecer a função do pâncreas. Apesar de recusar insulina por ser um «medicamento químico», diz aceitar comprimidos se os houver para sua doença...

A dada altura na consulta, em jeito de desabafo, refere que não sabe como apanhou a diabetes. Questiona a possibilidade de transmissão intra-hospitalar, através de transfusão, quando esteve em coma. Tenta-se contrariar esta crença, mas será que se conseguiu?

Numa tentativa de envolver a família, a médica questiona se A. já conversou com a esposa sobre a sua doença, ao que ele responde que nunca conversaram sobre isso e que cada um sabe da sua vida.

O doente, apesar do seu aparente alheamento, comportou-se sempre de forma muito afável, não tendo sido nunca ofensivo na expressão da sua recusa perante a proposta terapêutica.

Relativamente às queixas torácicas relacionadas com traumatismo, é-lhe aconselhado repouso e prescrita uma associação de analgésico com relaxante muscular.

No final da consulta, após várias explicações sobre o mecanismo da diabetes secundária, A. pergunta se não lhe será receitado nenhum comprimido para a sua diabetes e é-lhe novamente explicado o mecanismo da sua doença. Solicita uma receita de tiras de glicemia para vigilância dos valores glicémicos quando recomeçar o «medicamento da terra», alegando que irá controlar a sua doença. O único compromisso conseguido foi que A. voltasse à consulta 1 mês depois, para nova abordagem das suas representações da diabetes e da insulina.

Após ter desligado a câmara de filmar, A. bate à porta solicitando um certificado de incapacidade temporária para o trabalho decorrente do traumatismo torácico, o que provavelmente seria o seu principal motivo de consulta.

\section{Quarta Consulta com o Médico de Família}

(25 de Março de 2008)

A. volta à consulta a 25/03/2008, que é realizada pelo seu MF. A. mantém a recusa de reiniciar insulinoterapia, pelo que após várias insistências sem sucesso, se propõe que seja encaminhado para a Associação Protectora dos Diabéticos de Portugal (APDP), que A. aceita. Foi feita a referência médica e pediu-se a A. que nos contactasse assim que fosse à consulta na APDP, o que ainda não aconteceu.

\section{COMENTÁRIO}

$\mathrm{O}$ caso de A. gerou algum desconforto à médica, nomeadamente pela frustração de não ter conseguido alterar a representação que A. tinha da sua doença e da insulina. Foi a primeira vez que lidou com «um doente que não se via como doente». A situação era demasiado grave para desistir à primeira resistência e tentou-se orientar o doente no sentido da mudança e da adesão às medidas terapêuticas propostas. Foi constante o interesse em conhecer as motivações do doente, que no seu essencial não foram esclarecidas durante a referida consulta.

A. manteve uma atitude reveladora de total despreocupação, permanecendo quase deitado na cadeira du- 
rante grande parte da consulta. ${ }^{3}$ A médica captou este comportamento, não se deixando intimidar por ele. Era lícito que um doente que não se via doente não estivesse preocupado com a consulta. Havia que trabalhar no sentido de mudar a sua percepção da doença, e isso faria com que mudasse a sua atitude perante a consulta.

Este caso ilustra uma situação em que o médico se comporta como possuidor de um conhecimento revelado sobre o que é bom ou mau para os doentes. Michael Balint chama-lhe a função apostólica, descrevendo-a como o sentimento de dever de converter à nossa fé todos os doentes ignorantes e descrentes. ${ }^{1}$ No entanto, será possível não ser apostólico quando o doente está a colocar a sua vida em risco ao recusar o tratamento?

Para poder prestar melhores cuidados a este doente e para apaziguar a sensação de desconforto, foi importante para a médica olhar para o que se passou nesta consulta com outros olhos. Neste sentido, foi analisar o processo da consulta à luz dos princípios da entrevista motivacional e partilhar as emoções no contexto de um grupo Balint.

\section{Ajudar na mudança: a abordagem da entrevista motivacional}

Será que conhecimentos mais aprofundados na área da entrevista motivacional teriam influenciado o resultado final da consulta? No ciclo de mudança, A. encontra-se em fase de pré-contemplação. Por isso devem ser estabelecidas prioridades e programar um plano terapêutico repartido por várias consultas. Tendo por base os princípios fundamentais da Entrevista Motivacional para esta fase, procurou-se analisar a Terceira Consulta.

Expressar empatia: Expressar empatia significa transmitir respeito e interesse pelo utente. Escutar no sentido de perceber a perspectiva do utente, sem juízos de valor ou críticas, gerando confiança. ${ }^{4}$ Ao longo da consulta, foi constante o interesse pelo doente e pelas suas crenças. No entanto, ao encarar a empatia como «entrar no mundo do outro» e observar o mundo a partir do ponto de vista deste, terá sido esta característica cumprida no seu pleno? Como entender um ponto de vista que coloca o doente em risco de vida? É possível manter respeito e interesse pelo doente, mas é tão difícil olhar para o mundo através dos seus olhos quando a percep- ção é totalmente oposta à do médico!

Identificar as discrepâncias: Ampliar as diferenças entre o comportamento presente e as metas, para que a mudança se torne importante. Em fase de pré-contemplação, o doente não encara o seu comportamento como um problema, pelo que é importante reforçar os riscos do seu comportamento. Como reforçar o risco perante um doente em negação?

Gerir a resistência à mudança: Envolver o utente no processo de resolução do problema. Apesar da consulta ter sido centrada no doente, houve provavelmente uma vontade quase obsessiva de tentar compreender as motivações do doente, mas também de o convencer a mudar o seu comportamento, o que não pode constituir um objectivo imediato até o doente passar à fase de contemplação.

Promover a confiança e a capacidade do utente: Uma das estratégias mais importantes é reforçar a confiança do utente e acreditar que ele é capaz de mudar. A necessidade de discutir este caso traduz a confiança que a médica mantém em que o doente terá a capacidade de mudar.

Evitar confrontos directos: Abordar directamente $o$ comportamento pode provocar aumento da resistência. Os utentes são livres para decidir o que o profissional the oferece e as opiniões oferecidas podem ser ou não aproveitadas. O aparecimento de resistência é um indicador de reflexão para mudança de estratégia. Uma das questões que este caso suscita é o que deve o médico fazer quando a escolha do doente coloca em risco a sua vida. Não pode o profissional refugiar-se no princípio da autonomia do doente, e cruzar os braços. Que estratégias usar para evitar que a atitude do doente o conduza à progressão da sua doença?

Formular perguntas abertas: Uma pergunta aberta, colocada de forma genuína, sugere que o profissional está aberto a qualquer resposta. Fazer perguntas abertas leva o utente a falar, a dar informações importantes sobre o que pensa. $\mathrm{O}$ doente respondia de forma vaga às perguntas que lhe foram sendo feitas durante a consulta, e por vezes de forma circular. Não se conseguiu que o doente dissesse muito do que sentia, pelo que se tornou mais difícil o incentivo à mudança.

Reflectir e sintetizar: Reflectir consiste em explorar em voz alta o que está a ser comunicado e sintetizar consiste em reforçar os aspectos mais relevantes já analisados 
e ligá-los entre si no sentido da mudança. Ao utilizar as técnicas da entrevista motivacional, o médico avalia melhor qual a fase do processo de mudança em que $o$ doente se situa. Pode, por isso ajustar a intervenção às suas necessidades e interesses, em vez de oferecer ajuda, informação e conselhos de uma forma rotineira. Neste caso, o médico tem de ajudar o doente a que este se consciencialize da sua doença, pois sem isso ele nunca irá mudar o seu comportamento. Para tal, o papel do médico terá de ser constante e coerente no sentido da promoção da mudança.

\section{Apresentação num grupo Balint}

Este caso foi apresentado e discutido numa sessão de um grupo Balint, sendo enfatizada a sensação de frustração gerada na consulta e o sentimento de não ter sido feito tudo o que era possível.

Nos Grupos Balint desenvolve-se uma metodologia muito simples de partilha e escuta, com o apoio de alguém com formação específica, que vai gerindo a dinâmica do grupo e que, em momentos adequados, vai devolvendo uma explicitação emocional do que vai sendo relatado.

Valorizando a relação com o doente e a consulta, os médicos são incentivados a reconhecer os sentimentos que lhes sejam evocados pelo contacto com os doentes, treinando-se para o seu uso em proveito do doente, a detectarem o significado emocional de muitos dos sintomas apresentados na consulta, a serem capazes de utilizar o grupo para expressão das ansiedades e frustrações profissionais, a reconhecerem os seus próprios limites e a valorizarem os efeitos da sua própria humanidade e personalidade na relação com o doente. ${ }^{5}$

Perante este caso, foram discutidas as diferentes representações de médicos e doentes acerca das doenças e dos medicamentos, i.e., quando estas representações são dramaticamente diferentes, nomeadamente quando as diferenças interferem na relação médico-doente.

Na sequência da discussão do caso, foi debatido o impacto das diferenças culturais e das crenças no desenvolvimento da relação médico-doente. Foi consensual que o médico não deverá numa primeira abordagem menosprezar essas crenças, mas, à medida que a relação progride, deverão ser abordadas e, de forma técnica, deverá ser demonstrada a sua ineficácia (quando for caso disso...).
Abordaram-se possíveis estratégias para lidar com a frustração. Foi unânime que a própria frequência de um grupo Balint é uma estratégia muito válida, pois a partilha destas emoções e a sua discussão entre pares promove a confiança do médico que apresenta o caso em prosseguir. Os outros membros do grupo também ganham maior capacidade de auto-observação, o que os ajudará com os seus próprios doentes.

Durante a discussão deste caso foram surgindo várias propostas para a abordagem deste doente, tendo sido a sua referenciação para a APDP a mais consensual, de forma a que A. conhecesse outros doentes com Diabetes e que a partilha de sentimentos e experiências contribuíssem para a aceitação da sua doença. Considerou-se que encaminhar este doente para uma equipa multidisciplinar seria um enorme contributo para a sua mudança. Esta proposta foi discutida entre a interna e o MF de A., tendo ambos concordado ser a estratégia mais adequada, perante a gravidade do quadro clínico e o comportamento do doente.

Foi fundamental a discussão deste caso, para ultrapassar a sensação de frustração gerada e também pelas propostas que foram surgindo ao longo da discussão. Foi dito por um facilitador do grupo Balint e constata-se isso sempre que se apresenta um caso, quando voltamos a consultar o doente, sentimo-nos acompanhados pelos elementos do grupo Balint e com mais ânimo para prosseguir.

\section{Considerações finais}

Trata-se de um «caso difícil», em que as prioridades de médico e do doente são opostas, pelo que o trabalho no sentido do consenso deve ser estabelecido, tendo em conta as expectativas do doente, as suas vivências e a sua cultura.

Se em toda e qualquer consulta estes factores devem ser contemplados, quando os objectivos do doente e do médico são discordantes, todos estes pormenores adquirem extrema importância no sucesso terapêutico.

Os contactos com A. proporcionaram (à médica) um momento de reflexão sobre a (sua) identidade médica e sobre as (suas) emoções, pelo que este caso constituiu uma fase de crescimento profissional, através da sua análise e da discussão com colegas.

A Entrevista Motivacional pode ser uma ferramenta muito útil nas consultas de Medicina Geral e Familiar, 
pois é uma técnica comunicacional centrada no doente que tem como objectivo a aquisição da mudança e permite ao médico obter um conhecimento mais aprofundado do doente.

A partilha dos chamados "casos difíceis» em grupo Balint foi outra fase fundamental na "desconstrução» deste caso, pela análise das emoções e pela discussão de estratégias para este, mas também para outros casos em que as emoções geradas sejam semelhantes.

É unânime que o MF cuida de indivíduos no contexto das suas famílias, comunidades e culturas, respeitando sempre a autonomia dos seus doentes. Mas persiste esta dúvida: o que fazer quando a autonomia os coloca em risco de vida?

\section{ENDEREÇO PARA CORRESPONDÊNCIA}

Inês Maio

E-mail: inesmaio@gmail.com

\section{REFERÊNCIAS BIBLIOGRÁFICAS}

1. Balint M. O médico, o seu doente e a doença. Lisboa: Climepsi Editores; 1998.

2. Salinsky J, Sackin P. Médicos com emoções. Lisboa: Fundação Grunenthal; 2004.

3. Nunes JM. Comunicação em contexto clínico. Lisboa: Bayer Health Care; 2007.

4. Miller WR, Rollnick S. Motivational interviewing: preparing people for change. New York: Guilford Press; 2002.

5. Brandão J. Relação médico-doente: sua complexidade e papel dos grupos Balint. Rev Port Clin Geral 2007 Nov-Dez; 23 (6): 733-44.

\section{AGRADECIMENTOS}

Aos facilitadores e aos meus colegas do grupo Balint, pelo excelente trabalho de grupo que muito tem contribuído para a consciencialização do meu desempenho e das minhas emoções como médica de família. A todos eles um agradecimento muito especial.

\section{ABSTRACT}

Introduction: Due to its complexity and capital importance for the therapeutic success, the doctor-patient relationship continues to be an object of permanent analysis.

The description of the following case illustrates a doctor-patient relationship in which the priorities of the doctor and those of the patient oppose one another and how such a setting hinders the sucess of the therapeutic relationship.

With the account of this case we intend to show an example of the diversity of situations in General and Family Medicine, a specialty defined by the permanent and complex interaction of medical reasonings and emotions.

Case description: A 28 years old Cape Verde-born male patient who, when he was 22, was admitted in the hospital for an extended period of time following a diagnosis of acute necrotizing pancreatitis of alcoholic etiology. He was subsequently diagnosed with secondary diabetes and started an insulin treatment which he abandoned afterwards.

The patient resumed consultations with his family physician in 2008 and claimed to have taken a "homemade medicine". Given the analytic evaluation, which revealed hyperglycemia and $16,5 \% \mathrm{HbA}_{1 \mathrm{c}}$, the patient was approached with the intent to resume insulin therapy, which he inflexibly refused.

According to the patient, 4 years earlier he was told that he wouldn't live long without the insulin therapy; given the fact that he is "alive and well", he fails to understand the need to take it now.

Not being able to get the patient to agree to the recommended therapeutics and given the seriousness of the clinical setting, the doctor prompted the patient to start treatment in an institution for diabetic care; accordingly, he was referenced to the PDA (Portuguese Diabetic Association).

Discussion: This case has given way to a feeling of frustration in the doctor due to not having been able to change the patient's behaviour, a fact that is sure to have harsh consequences.

In a reflection based on the change-cicle, we analyse how the Motivational Interview might have determined a different result. The sharing of the case on a Balint group session is discussed - such an experience was pivotal because it eased the overcoming of the feeling of frustration and also due to the suggestions that came about during the discussion.

The notion that the family physician provides care for individuals in the context of their families, communities and cultures, always respecting the autonomy of his or her patients is unanimous. But what should the doctor do when the patients' autonomy endangers their own lives?

Keywords: Doctor-Patient Relation; Balint; Apostolic Functions; Change-Cicle; Motivational Interview; Diabetes. 